\title{
Preexposure to, but Not Cotreatment with, the Neurotensin Antagonist SR 48692 Delays the Development of Cocaine Sensitization
}

\author{
Brian A. Horger, Ph.D., Jane R. Taylor, Ph.D., John D. Elsworth, Ph.D.,
} and Robert H. Roth, Ph.D.

This study examined the role of neurotensin (NT) in the development of cocaine sensitization using the novel nonpeptide NT antagonist SR 48692. Male SpragueDawley rats received five daily administrations of $S R$ $48692(80 \mu \mathrm{g} / \mathrm{kg}, I P$ or PO) or vehicle. Following a 7 day drug-free period, cocaine-induced (15 $\mathrm{mg} / \mathrm{kg}, I P)$ locomotor activity was assessed. Subsequent cocaine tests occurred every other day. No differences were observed between groups during the first day of cocaine testing. Sensitization to the locomotor activating effects of cocaine occurred rapidly in the controls reaching peak effects by the third cocaine challenge injection. By contrast, subjects preexposed to SR 48692 IP were delayed in the development of cocaine sensitization maintaining significantly lower cocaine-induced activity counts relative to controls until the sixth cocaine challenge injection. Preexposure to SR 48692 PO also produced an attenuating effect on the development of cocaine sensitization. The decreased cocaine-induced activity in
SR 48692-preexposed subjects did not appear to be the result of a locomotor deficit as SR 48692-preexposed subjects exhibited increased activity rates following a high dose $(30 \mathrm{mg} / \mathrm{kg}, \mathrm{IP})$ cocaine challenge injection. In an additional experiment, the effect of cotreatment with.SR 48692 on the development of cocaine sensitization was assessed. Subjects were cotreated with SR 48692 (80 $\mu \mathrm{g} / \mathrm{kg}, I P)$ or vehicle 60 minutes prior to each of two cocaine (15 mg/kg, IP) or saline preexposure injections. Following a drug-free day, subjects were tested for cocaine-induced (15 $\mathrm{mg} / \mathrm{kg}, \mathrm{IP}$ ) locomotor activation. SR 48692 cotreatment had no effect on the development of sensitization to cocaine. These data suggest that chronic preexposure to SR 48692 produces lasting effects rendering subjects resistant to the development of sensitization to the activating effects of cocaine. Further, these data provide direct evidence for a role of NT in the development of cocaine sensitization.

[Neuropsychopharmacology 11:215-222, 1994]
KEY WORDS: SR 48692; Neurotensin; Cocaine; Sensitization; Locomotion

Repeated exposure to a psychostimulant, such as cocaine, produces an augmentation of its behavioral activating effects (Tatum and Seevers 1929; Post and Rose

From the Department of Pharmacology (BAH, JDE, RHR), Yale University School of Medicine, Department of Psychiatry (JRT, JDE, RHR), Yale University School of Medicine.

Address reprint requests to: Brian A. Horger, Ph.D., Department of Pharmacology, Yale University School of Medicine, 333 Cedar Street, New Haven, Connecticut 06520-8066.

Received February 14, 1994; revised May 13, 1994; accepted July $12,1994$.
1976; Shuster et al. 1977). Behavioral sensitization is accompanied by an enhanced ability of cocaine to elevate extracellular levels of dopamine (DA) in the ventral striatum (VS) (Kalivas and Duffy 1990a). This hypersensitivity of midbrain DA systems has led some to propose behavioral sensitization as a model for amphetamine psychosis and schizophrenia (Robinson and Becker 1986; Robinson 1991; Sato et al. 1992).

Recently the tridecapeptide neurotensin (NT) has been postulated to have a role in stimulant-induced sensitization. NT administered into the ventral tegmental area (VTA) produces stimulant-like behavioral activating effects such as increased locomotor activity and rear- 
ing (Kalivas et al. 1983; Cador et al. 1985; Elliot and Nemeroff 1986). In addition, intra-VTA infusions of NT increase extracellular levels of DA in the VS (Laitinen et al. 1990; Kalivas and Duffy 1990b). With repeated exposures, the locomotor activating effects of VTA-administered NT become augmented (Kalivas and Taylor 1985; Elliot and Nemeroff 1986; Kalivas and Duffy $1990 \mathrm{~b}$ ). This increase in NT's behavioral effects is accompanied by an enhanced ability of intra-VTA NT to elevate extracellular levels of DA in the VS (Kalivas and Duffy 1990b).

In vitro and in vivo electrophysiological studies have indicated that NT modulates mesencephalic DA cell firing (Seutin et al. 1989; Shi and Bunney 1990). When applied alone into the VTA, NT excited relatively few DA cells except at high currents. Yet, in a majority of these cells, NT attenuated quinpirole-induced autoreceptor inhibition (Shi and Bunney 1991). This effect could have been due to a neuromodulatory effect on D2 receptor binding as low nanomolar concentrations of NT have been shown to reduce the affinity of D2 receptors for agonists without affecting antagonist binding (Euler 1991; Euler et al. 1991).

The VTA has been implicated as a critical site in the development of behavioral sensitization to cocaine. Repeated injections of amphetamine into the VTA, but not the VS, produce a sensitized locomotor activating response to a subsequent systemic cocaine challenge (Kalivas and Weber 1987; Hooks et al. 1992). Recently, we have found that an acute systemic injection of cocaine results in an increase in NT-like immunoreactivity in samples recovered from the VTA using in vivo microdialysis (Roth et al. 1993). Thus, it is possible that NT in the VTA could have a role in the development of cocaine sensitization.

Recently, a selective NT receptor antagonist has become available (SR 48692). This nonpeptide bioavailable compound has been characterized as a potent and selective antagonist for the NT receptor that readily crosses the blood brain barrier (Gulley et al. 1993). A low dose of SR 48692 administered systemically has been shown to block the behavioral activating effects of centrally administered NT. Thus, SR 48692 has potential as a valuable pharmacological tool for investigating the actions of central NT. The present set of experiments uses SR 48692 to investigate the role of NT in the development of cocaine sensitization.

\section{METHODS}

\section{Subjects}

Male Sprague-Dawley rats purchased from CAMM (Wayne, NJ) at a weight of $225 \mathrm{~g}$ to $250 \mathrm{~g}$ were used as subjects for each experiment. The colony room was on a 12 hour light/dark schedule and temperature con- trolled to $21^{\circ} \mathrm{C}$. The animals were housed two per cage with free access to laboratory chow and water. All subjects were housed in the colony room for at least 5 days before beginning their respective procedures.

\section{Drugs}

SR 48692 (courtesy of Sanof Recherche, Montpellier, France) was administered at a dose of $80 \mu \mathrm{g} / \mathrm{kg}$ either intraperitoneally (IP) or perorally (PO). This dose has previously been shown to block the activating effects of centrally-administered NT (Gulley et al. 1993). For IP injections, SR 48692 was solubilized in dimethyl sulfoxide (DMSO) by warming and diluted with deionized water. The final concentration of DMSO was $37 \%$ of the vehicle in an injection volume of $1 \mathrm{ml} / \mathrm{kg}$. SR 48692 was administered $\mathrm{PO}$ via oral gavage in $0.5 \%$ methylcellulose (in deionized water) in an injection volume of $3 \mathrm{ml} / \mathrm{kg}$. Cocaine $\mathrm{HCl}$ (Sigma, St. Louis, MO) was dissolved in physiological saline and administered in an injection volume of $1 \mathrm{ml} / \mathrm{kg}$. All cocaine injections in Experiment I and Experiment II were administered IP at a dose of $15 \mathrm{mg} / \mathrm{kg}$ (salt weight). In Experiment III, cocaine-induced locomotor activity was assessed at a dosage of $30 \mathrm{mg} / \mathrm{kg}$ (salt weight).

\section{Apparatus}

Locomotor activity was measured using the automated Omnitech (Columbus, OH) Digiscan Micro-monitor system equipped with 16 photocells. Movement within the test cage produced interruptions of the photocell beams. The number of interruptions (activity counts) was recorded in 10 minute intervals. The same type of Plexiglass cage used to house the subjects in the colony room was used as the test cage. This kept conditioning cues between home cage cocaine injections (Experiment II) and testing for cocaine-induced locomotor activation relatively constant (see Post et al. 1981). Prior to each test session, the activity test cages were cleaned with $70 \%$ ethanol. The test cages were located inside a sound attenuated chamber equipped with a white noise generator. The testing chamber was illuminated with red light.

\section{Experiment 1: Effects of SR 48692 Preexposure on the Development of Cocaine Sensitization}

Subjects were preexposed to SR 48692 or vehicle daily for 5 days. SR 48692 or vehicle was administered either IP or PO in the home cage. Following the fifth SR 48692 or vehicle administration there was a 7-day drug-free interval. Subsequently, cocaine-induced locomotor activity testing began. On test days, the animals were placed in the activity monitor test cages for 60 minutes prior to cocaine administration and activity counts were 
recorded. This procedure served to habituate subjects and to establish preinjection baseline activity levels. Following the baseline period, subjects were given a cocaine injection and tested for an additional 60 minutes. Cocaine-induced locomotor activity was assessed every other day.

\section{Experiment 2: Effects of SR 48692 Cotreatment on the Development of Cocaine Sensitization}

In contrast to the preexposure design of Experiment 1 , subjects in the present experiment were cotreated with SR 48692 prior to each of two cocaine preexposure injections. Subjects received an IP injection of SR 48692 or vehicle 60 minutes prior to a cocaine or saline injection in the home cage. This procedure was repeated again following one drug-free day. The treatment groups formed were: (1) SR 48692/cocaine, (2) vehicle/cocaine, (3) SR 48692/saline, and (4) vehicle/saline.
Following an additional drug-free day all subjects were tested for cocaine-induced locomotor activation. Subsequent to a 60 -minute baseline period, subjects were given a single cocaine injection and tested for cocaine-induced locomotor activity for an additional 60 minutes. Data from this procedure was equivalent to that obtained on cocaine challenge day 3 in Experiment 1 .

In this procedure, cocaine-induced locomotor activity was assessed 48 hours after the last SR 48692 cotreatment injection. Whereas the effects of SR 48692 have been shown to be relatively long lasting (Gulley et al. 1993), pilot data indicated that SR $48692(80 \mu \mathrm{g} / \mathrm{kg}$, IP) pretreatment 1 hour prior to a cocaine injection (15 $\mathrm{mg} / \mathrm{kg}$, IP) does not affect cocaine's ability to produce locomotor activation (unpublished observations). Thus, if residual SR 48692 were present after 2 days, it should not have affected the assessment of cocaine-induced locomotor activation.
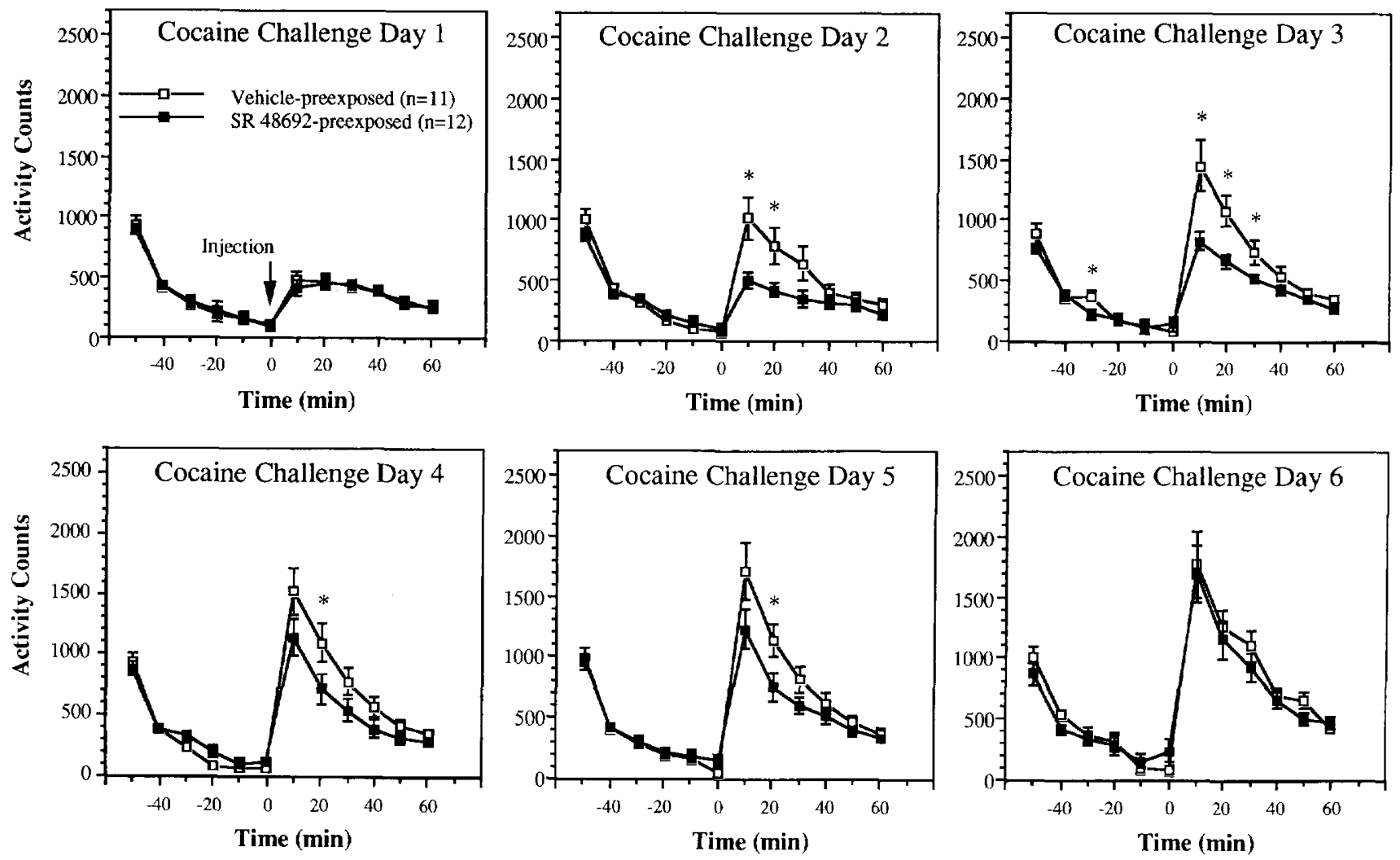

Figure 1. Intraperitoneal preexposure to SR 48692. Mean ( \pm SEM) activity counts 60 minutes prior to and following each of six cocaine $(15 \mathrm{mg} / \mathrm{kg}, \mathrm{IP})$ injections in subjects preexposed to SR $48692(80 \mu \mathrm{g} / \mathrm{kg}, \mathrm{IP})$ or vehicle for 5 days. The first cocaine challenge was administered 7 days after the last SR 48692 or vehicle preexposure injection. Subsequent challenges were conducted every other day. Individual 2-way (Preexposure $\times$ Time) ANOVAs conducted on each cocaine challenge day revealed a significant interaction on cocaine challenge day 2 through day $5[\mathrm{~F}(11,231)=35.43, p<.0001 ; 5.21, p<.0001$; $3.14, p<.001 ; 3.03, p<.001$; respectively] and a significant effect of Preexposure on cocaine challenge day $3[\mathrm{~F}(1,21)=$ $6.77, p<.05]$. Significant differences as determined by Scheffe's posthoc analyses are indicated with an asterisk $(p<.05)$. The number of subjects tested on each cocaine challenge were as indicated in the figure legend except cocaine challenge day 6 in which the number of subjects were 6 and 8 in vehicle-preexposed groups and SR 48692-preexposed groups, respectively. 


\section{Experiment 3: Ability of Subjects to Engage in High Rates of Locomotor Activity Following Preexposure to SR 48692}

To assess the effects of repeated exposure to SR 48692 on high rates of activity, locomotor activity was assessed following a larger dose of cocaine. Subjects daily received five IP injections of SR 48692, or vehicle in the home cage as described in Experiment 1. Seven days after the last preexposure injection subjects were tested for cocaine-induced locomotor activity. Following a 60 minute baseline period, subjects received a cocaine $(30$ $\mathrm{mg} / \mathrm{kg}$, IP) injection. Locomotor activity was then recorded for an additional 60 minutes.

\section{RESULTS}

\section{Experiment 1: Preexposure to SR 48692 Retards the Development of Cocaine Sensitization}

Figure 1 depicts activity counts on each cocaine challenge day in subjects that had received IP preexposure injections of SR 48692 or vehicle. There were no sig- nificant differences between vehicle-preexposed and SR 48692-preexposed subjects in activity counts produced by an acute cocaine exposure (cocaine challenge day 1). Following the second cocaine exposure, vehiclepreexposed controls exhibited a sensitized response relative to the SR 48692-preexposed subjects. Controls approached peak activating effects by cocaine challenge day 3. In contrast, activity counts in the SR 48692-preexposed subjects remained significantly lower until cocaine challenge day 6 .

Similar effects were observed in subjects preexposed to SR 48692 via PO administration. As depicted in Figure 2, sensitization occurred more rapidly in the vehicle-preexposed controls relative to the SR 48692preexposed (PO) subjects. However, the attenuating effect on the development of cocaine sensitization following PO preexposure to SR 48692 was not as robust relative to that produced by IP preexposure (Figure 1 ). Activity counts in the SR 48692-preexposed (PO) subjects were significantly reduced on cocaine challenge day 3 only.

To confirm that sensitization had indeed occurred in both SR 48692-preexposed and vehicle-preexposed
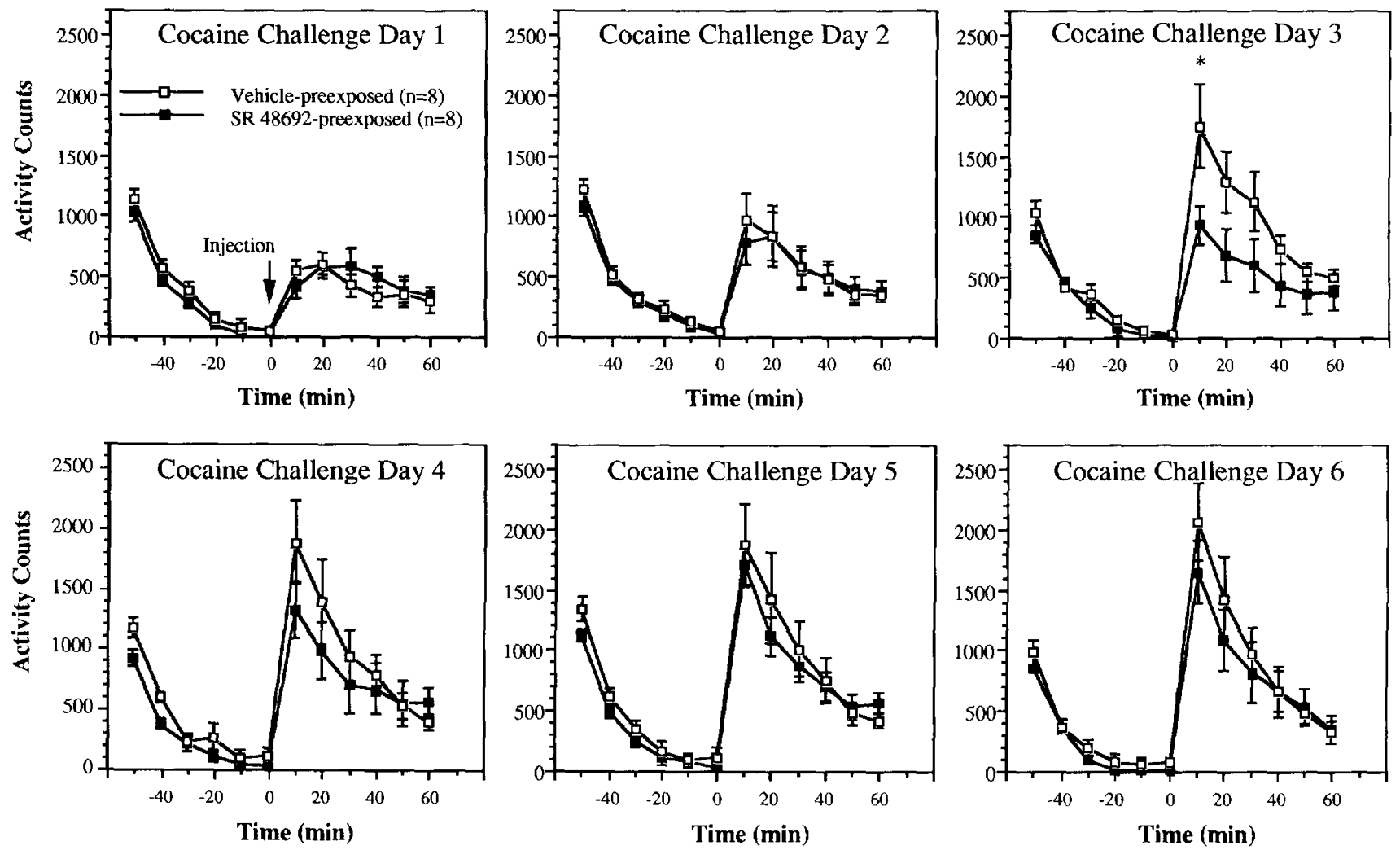

Figure 2. Peroral preexposure to SR 48692. Mean ( \pm SEM) activity counts 60 minutes prior to and following each of six cocaine (15 mg/kg, IP) injections in subjects preexposed to SR 48692 ( $80 \mu \mathrm{g} / \mathrm{kg}, \mathrm{PO})$, or vehicle for 5 days. The first cocaine challenge was administered 7 days after the last SR 48692 or vehicle preexposure administration. Subsequent challenges were conducted every other day. Individual 2-way (Preexposure $\times$ Time) ANOVAs revealed a significant interaction on cocaine challenge day $3[F(11,154)=2.67, p<.01]$. Significant differences as determined by Scheffe's posthoc analyses are indicated with an asterisk $(p<.05)$. 
groups by the sixth cocaine injection, activity counts on cocaine challenge day 1 and day 6 were compared. A 3-way (Preexposure $\times$ Challenge $\times$ Time) ANOVA of total activity counts postinjection revealed a sig. nificant effect of Challenge for both IP-preexposed subjects $[\mathrm{F}(1,20)=28.15, p<.0001)$ and PO-preexposed $[F(1,28)=10.49, p<.01]$ subjects (data not shown). The lack of a significant Preexposure $\times$ Challenge interaction for both IP-preexposed groups and PO-preexposed groups suggested that SR 48692-preexposed subjects and vehicle-preexposed subjects were sensitized to a similar degree by cocaine challenge day 6 .

\section{Experiment 2: Cotreatment with SR 48692 Does Not Affect the Development of Cocaine Sensitization}

Sensitization to the locomotor activating effects of cocaine developed regardless of whether the subjects were cotreated with SR 48692 or with vehicle. As depicted in Figure 3, cocaine-preexposed subjects (Vehicle/Cocaine and SR 48692/Cocaine groups) exhibited increased activity counts in the first 10 minute period after the cocaine challenge injection relative to the saline-preexposed controls (Vehicle/Saline and SR 48692/Saline groups). SR 48692 co-treatment did not alter activity

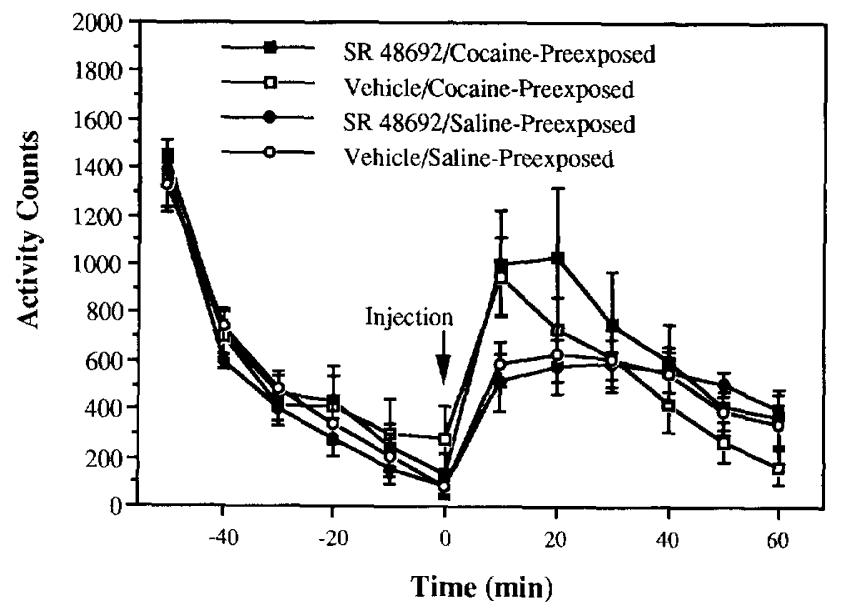

Figure 3. SR 48692 cotreatment. Mean ( \pm SEM) activity counts 60 minutes before and after a cocaine $(15 \mathrm{mg} / \mathrm{kg}, \mathrm{IP})$ injection. Subjects had received two cotreatment injections of either SR $48692(80 \mu \mathrm{g} / \mathrm{kg}$, IP) or vehicle 60 minutes prior to a cocaine $(15 \mathrm{mg} / \mathrm{kg}, \mathrm{IP})$ or saline injection $(n=8$ in each group). Cotreatment injections were administered in the home cage 2 and 4 days prior to testing for cocaine-induced locomotor activity. A 3-way (SR 48692 Preexposure $\times$ Cocaine Preexposure $\times$ Time) ANOVA revealed a significant interaction between the Cocaine Preexposure and Time variables only $[\mathrm{F}(11,308)=2.94, p<.001]$ with no significant treatment effects. Analyses of simple main effects indicated that subjects preexposed to cocaine exhibited significantly higher activity counts above that of saline-preexposed subjects in the first 10 minute postinjection time point only $(p<.01)$. counts exhibited by subjects preexposed to cocaine or saline. Thus, cotreatment with SR 4869260 minutes prior to cocaine preexposure injections did not attenuate the development of cocaine sensitization.

\section{Experiment 3: Lack of a Locomotor Deficit Following Repeated Exposure to SR 48692}

Both SR 48692-preexposed subjects and vehicle-preexposed subjects demonstrated high rates of activity counts following a $30 \mathrm{mg} / \mathrm{kg}$ cocaine injection. As depicted in Figure 4, no significant differences in activity counts were observed between groups. Notably, peak activating effects did not occur until 40 minutes postinjection. Most likely this was due to the induction of stereotypy during the peak effects of this high dose of cocaine, although subjects were not observed for stereotypy to confurm this. Nevertheless, locomotor activity did eventually exceed the sensitized rates of locomotor activity produced by vehicle-preexposed subjects on cocaine challenge day 2 and approached rates observed on day 3 (Figure 1).

\section{DISCUSSION}

Preexposure to the NT antagonist SR 48692 produced a significant delay in the development of sensitization to the locomotor activating effects of cocaine. In contrast, co-treatment with SR 486921 hour before two daily cocaine injections failed to produce an antagonistic effect on the development of cocaine sensitization. Thus, chronic exposure to SR 48692 followed by a

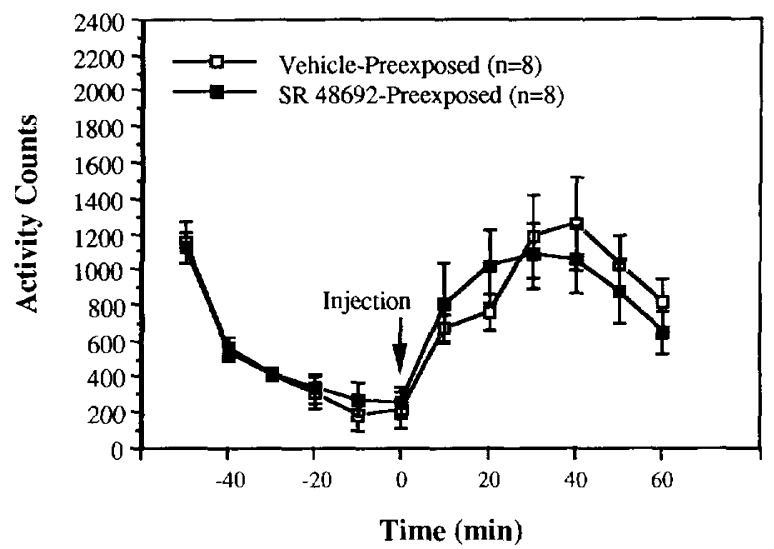

Figure 4. Thirty $\mathrm{mg} / \mathrm{kg}$ cocaine challenge. Mean ( \pm SEM) activity counts 60 minutes prior and subsequent to a high dose (30 mg/kg, IP) cocaine challenge injection in subjects preexposed to SR $48692(80 \mu \mathrm{g} / \mathrm{kg}$, IP) or vehicle for 5 days. Cocaineinduced locomotor activity was assessed 7 days after the last SR 48692, or vehicle preexposure injection. A 2-way (Preexposure $\times$ Time) ANOVA failed to indicate a significant interaction $[F(11,154)=0.70, N S]$ or Preexposure effect $[F(1,14)=$ $0.01, \mathrm{NS}]$. 
1-week drug-free interval produced long lasting effects resulting in subjects being more resistant to the development of cocaine sensitization.

It is unlikely that SR 48692 preexposure interfered with the ability of the subjects to engage in locomotor activity. Chronic preexposure to SR 48692 did not interfere with the acute activating effects of cocaine as demonstrated by the lack of significant differences between groups on cocaine challenge day 1 (Figures 1 and 2). In addition, SR 48692-preexposed subjects eventually exhibited the same high rates of locomotor activity as that observed in the vehicle-preexposed controls. The possibility that chronic SR 48692 preexposure could have produced a transient locomotor deficit rendering the rats incapable of locomoting at high rates until after the third cocaine challenge injection (11 days postpreexposure) is unlikely. Subjects preexposed to SR 48692 and challenged with a high dose of cocaine demonstrated higher rates of activity counts with no significant differences relative to the vehicle-preexposed controls (Figure 4). Locomotor activity in the SR 48692preexposed subjects exceeded the rates produced by the sensitized vehicle-preexposed subjects on cocaine challenge day 2 and approached rates observed on cocaine challenge day 3 (Figure 1 ). These data suggest that the reduced activating response of cocaine in the SR 48692-preexposed subjects (Figures 1 and 2) was not the result of a locomotor deficit. Rather, chronic exposure to SR 48692 appears to produce a relatively longlasting attenuating effect specific to the development of cocaine sensitization.

The mechanism by which SR 48692 preexposure exerts its effects on the development of cocaine sensitization is unclear. Using in vivo microdialysis, we have observed increases in extracellular levels of NT in the VTA following an acute cocaine injection (Roth et al. 1993). The hypothesis that cocaine sensitization is dependent upon an elevation of extracellular NT in the VTA would predict that preexposure to SR 48692 attenuates the NT increases that occur with repeated cocaine administration. Future investigations will explore this as a possible mechanism by which SR 48692 preexposure antagonizes the development of behavioral sensitization to cocaine.

Preliminary data suggest that chronic exposure to SR 48692 increases NT mRNA receptor levels in the VTA (Bolden-Watson et al. 1993). An upregulation of NT receptors in the VTA would be expected to result in an augmentation of NT's neuromodulatory effects at this site. Although this may be predicted to produce a sensitized effect rather than a blockade of cocaine sensitization, we have only a fragmentary understanding of the mechanisms by which NT affects DA cell activity. It should be considered, for example, that different subtypes of NT receptors have been characterized (Schotte et al. 1986), the function of which remains unknown.
The selectivity of SR 48692 for these subtypes has yet to be determined. Whereas a majority of NT receptors in the VTA seem to be located on DA cells (Szigethy and Beaudet 1989), few of these receptors are proximal to NT containing axon terminals. Less than $10 \%$ of NT immunoreactive axons in the VTA are in direct apposition with tyrosine hydroxylase immunoreactive elements, whereas many appositions occur between NTpositive varicosities and nonlabeled elements (Woulfe and Beaudet 1989, 1992); thus, it is possible that SR 48692 is not selective for the NT receptor subtype(s) that has a direct neuromodulatory influence on DA cell function.

Although sensitization to the behavioral and neurochemical effects of cocaine has been increasingly characterized, the mechanisms responsible for its development have remained elusive. NT has been postulated to have a role in the development of sensitization due to the induction of stimulant-like behavioral sensitization upon repeated administration of NT into the VTA. The present data demonstrate that preexposure to SR 48692 attenuates the development of cocaine sensitization and provide compelling evidence for a role of NT in stimulant-induced sensitization.

The development of cocaine sensitization has been shown to be blocked by co-treatment with glutamate and dopamine receptor antagonists (Karler et al. 1989, 1990; Karler and Calder 1992; Wolf and Jeziorski 1993). In these studies, MK- 801 or haloperidol were administered prior to each cocaine preexposure injection. SR 48692 appears to act uniquely in that administration does not have to immediately precede cocaine exposure. In fact, the attenuating effects of SR 48692 preexposure on the development of cocaine sensitization appear to be relatively long lasting.

Sensitization to the locomotor activating effects of cocaine can also be induced by preexposure to other stimulants or stress (Shuster et al. 1977; Sorg and Kalivas 1991). It would be of interest to determine whether preexposure to SR 48692 retards the development of sensitization induced by these procedures as well. Behavioral sensitization has been proposed as a model for schizophrenia and amphetamine psychosis (Robinson and Becker 1986; Robinson 1991; Sato et al. 1992). In this regard, identification of the mechanisms by which SR 48692 preexposure produces lasting attenuating effects on the development of cocaine sensitization may lead to increased understanding of the etiology of these disorders and aid in the development of rational therapeutic strategies for their treatment.

\section{ACKNOWLEDGMENT}

This project funded in part by the U.S. Public Health Service (MH 14092 to RHR). We would like to thank Maria Siambekos 
and Ryan Heffelfinger for their technical assistance and Sanof Recherche for the generous gift of SR 48692 .

\section{REFERENCES}

Bolden-Watson C, Watson M, Richelson E (1993): Effect of the neurotensin receptor antagonist SR 48692 on the expression of neurotensin and neurotensin receptor mRNA in rat brain. Society for Neuroscience Abstracts 19:1184

Cador M, Kelley AE, Le Moal M, Stinus L (1985): Behavioral analysis of the effect of neurotensin injected into the ventral mesencephalon on investigatory and spontaneous motor behavior in the rat. Psychopharmacology 85: 187-196

Elliot PJ, Nemeroff CB (1986): Repeated neurotensin administration in the ventral tegmental area: Effects on baseline and d-amphetamine-induced locomotor behavior. Neurosci Lett 68:239-244

Euler G von (1991): Biochemical characterization of the intramembrane interaction between neurotensin and dopamine D2 receptors in the rat brain. Brain Res 561:93-98

Euler G von, van der Ploeg I, Fredholm BB, Fuxe K (1991): Neurotensin decreases the affinity of dopamine D2 binding by a $G$ protein-dependent mechanism. J Neurochem 56:178-183

Gulley D, Canton M, Boigegrain R, Jeanjean F, Molimard J-C, Poncelot M, Gueudèt C, Heaulme M, Leyris R, Brouard A, Pelaprat D, Labbé-Jullié C, Mazella J, Soubrié P, Maffrand JP, Rosténe W, Kitabgi P, LeFur G (1993): Biochemical and pharmacological profile of a potent and selective nonpeptide antagonist of the neurotensin receptor. Proc Natl Acad Sci USA 90:65-69

Hooks MS, Jones GH, Liem BJ, Justice JB Jr (1992): Sensitization and individual differences to i.p. amphetamine, cocaine, or caffeine following repeated intra-cranial amphetamine infusions. Ann New York Acad Sci 654:444447

Kalivas PW, Burgess SK, Nemeroff CB, Prange AJ Jr (1983): Behavioral and neurochemical effects of neurotensin microinjection into the ventral tegmental area. Neuroscience 8:496-505

Kalivas PW, Duffy P (1990a): Effect of acute and daily cocaine treatment on extracellular dopamine in the nucleus accumbens. Synapse 5:45-58

Kalivas PW, Duffy P (1990b): Effect of acute and daily neurotensin and enkephalin treatments on extracellular dopamine in the nucleus accumbens. J Neurosci 10 : 2940-2949

Kalivas PW, Taylor S (1985): Behavioral and neurochemical effect of daily injection with neurotensin in to the ventral tegmental area. Brain Res 358:70-76

Kalivas PW, Weber B (1987): Amphetamine injection into the ventral mesencephalon sensitizes rats to peripheral amphetamine and cocaine. J Pharmacol Exp Ther 245: 1095-1102

Karler R, Calder LD (1992): Excitatory amino acids and the actions of cocaine. Brain Res 582:143-146

Karler R, Calder LD, Chaudhry IA, Turkanis SA (1989): Blockade of "reverse tolerance" to cocaine and amphetamine by MK-801. Life Sci 45:599-606
Karler R, Chaudhry IA, Calder LD, Turkanis SA (1990): Amphetamine behavioral sensitization and the excitatory amino acids. Brain Res 537:76-82

Laitinen K, Crawley JN, Mefford IN, de Witte P (1990): Neurotensin and cholecystokinin microinjected into the ventral tegmental area modulate microdialysate concentrations of dopamine and metabolites in the posterior nucleus accumbens. Brain Res 523:342-346

Post RM, Lockfield A, Squillace KM, Contel NR (1981): Drugenvironment interaction: Context dependency of cocaineinduced behavioral sensitization. Life Sci 28:755-760

Post RM, Rose H (1976): Increasing effects of repetitive cocaine administration in the rat. Nature 260:731-732

Robinson TE, Becker JB (1986): Enduring changes in brain and behavior produced by chronic amphetamine administration: A review and evaluation of animal models of amphetamine psychosis. Brain Res Rev 11:157-198

Robinson TE (1991): The neurobiology of amphetamine psychosis: Evidence from studies with an animal model. In Nakazawa T (ed), Biological Basis of Schizophrenic Disorders, Farmington, S. Karger, pp 185-201

Roth RH, Bean AJ, During MJ, Bradberry CW (1993): Corelease of mesocorticolimbic neurotensin and dopamine. Summer Neuropeptide Conference Abstracts, pp 10

Sato M, Numachi Y, Hamamura T (1992): Relapse of paranoid psychotic state in methamphetamine model of schizophrenia. Schizophr Bull 18:115-122

Schotte A, Leysen JE, Laduron PM (1986): Evidence for a displaceable non-specific $\left[{ }^{3} \mathrm{H}\right]$ neurotensin binding site in rat brain. Naunyn Schmiedebergs Arch Pharmacol 333: 400-405

Sorg BA, Kalivas PW (1991): Effects of cocaine and footshock stress on extracellular dopamine levels in the ventral striatum. Brain Res 559:29-36

Seutin V, Massotte L, Dresse A (1989): Electrophysiological effects of neurotensin on dopaminergic neurons of the ventral tegmental area of the rat in vitro. Neuropharmacology 28:949-954

Shi W-X, Bunney BS (1990): Neurotensin attenuates dopamine D2 agonist quinpirole-induced inhibition of midbrain dopamine neurons. Neuropharmacology 29:10951097

Shi W-X, Bunney BS (1991): Neurotensin modulates autoreceptor mediated dopamine effects on midbrain dopamine cell activity. Brain Res 543:315-321

Shuster L, Yu G, Bates A (1977): Sensitization to cocaine stimulation in mice. Psychopharmacology 52:185-190

Szigethy E, Beaudet A (1989): Correspondence between high affinity ${ }^{125} \mathrm{I}$-neurotensin binding sites and dopaminergic neurons in the rat substantia nigra and ventral tegmental area: A combined radioautographic and immunohistochemical light microscopic study. J Comp Neurol 279:128-137

Tatum AL, Seevers MH (1929): Experimental cocaine addiction. J Pharmacol Exp Ther 26:401-410

Wolf M, Jeziorski M (1993): Coadministration of MK-801 with amphetamine, cocaine or morphine prevents rather than transiently masks the development of behavioral sensitization. Brain Res 613:291-294 
Woulfe J, Beaudet A (1989): Immunocytochemical evidence for direct connections between neurotensin-containing axons and dopaminergic neurons in the rat ventral midbrain tegmentum. Brain Res 479:402-406
Woulfe J, Beaudet A (1992): Neurotensin terminals form synapses primarily with neurons lacking detectable tyrosine hydroxylase immunoreactivity in the rat substantia nigra and ventral tegmental area. J Comp Neurol 321:163-176 